\title{
Evaluation of the larvicidal potential of root and leaf extracts of Saussurea costus (Falc.) Lipsch. against three mosquito vectors:Anopheles stephensi, Aedes aegypti, and Culex quinquefasciatus
}

\author{
Sofi Imtiyaz Ali[ ${ }^{[1]}$ and Venugopalan Venkatesalu ${ }^{[1]}$
}

[1]. Department of Botany, Annamalai University, Annamalainagar - 608 002, Tamil Nadu, India.

\begin{abstract}
Introduction: The larvicidal potential of Saussurea costus (Falc.) Lipsch. was studied against the early $4^{\text {th }}$ instar larvae of Anopheles stephensi Liston., Aedes aegypti Linn.,and Culex quinquefasciatus Say. because of the emergence of mosquito resistance to conventional synthetic insecticides. Methods: At concentrations of 12.5-200 ppm, larvicidal activities were studied under laboratory conditions. Results: After $24 \mathrm{~h}$ of exposure, the methanol extract of the roots recorded the highest larvicidal activity against An. stephensi, with $\mathrm{LC}_{50}$ and $\mathrm{LC}_{90}$ values of 7.96 and $34.39 \mathrm{ppm}$, respectively. Conclusions: We are developing potent larvicidal compound(s) from $S$. costus for controlling the mosquito larval population.
\end{abstract}

Keywords: Anopheles stephensi. Aedes aegypti. Culex quinquefasciatus. Saussurea costus. Vectors. Larvicidal activity.

The Culicidae familyis comprised of approximately 3500 mosquito species. The genera Anopheles, Aedes, and Culex act as vectors of various diseases, such as encephalitis, chikungunya, dengue fever, filariasis, and malaria ${ }^{1}$, which compromise human health ${ }^{2}$.The important vector of malaria in the urban districts of India and other West Asian countries is Anopheles stephensi ${ }^{3}$, which afflicts $36 \%$ of people situated in tropical and subtropical regions ${ }^{4}$. The female mosquitoes of the genus Aedes transmit the viruses of dengue, zika, and chikungunya fever in the tropical and subtropical urban regions of the world. At present, approximately 2500 million people are facing the threat of dengue fever and nearly 50 million cases are recorded every year ${ }^{5}$. The parasitic filarial nematodes (roundworms - Family Filarioidea) Wuchereria bancrofti ( $90 \%$ of infections), Brugia malayi ( $9 \%$ of infections), and Brugia timori ( $1 \%$ infections) cause lymphatic filariasis, for which the vector is Culex quinquefasciatus. There are approximately 120 million prevalent infections that are caused by these filarial worms, most of which are due to $W$. bancrofti ${ }^{6}$.

\footnotetext{
Correspondingauthor: Dr. Sofi Imtiyaz Ali

e-mail: sofiraja369@gmail.com

(D) 0000-0002-3439-5894

Received 09 January 2019

Accepted 25 November 2019
}

Mosquito control is facing timely challenges due to the inadequate success of bio-control programs and emergence of resistance to the conventional synthetic insecticides, which have necessitated the need to investigate and develop unconventional strategies by means of eco-friendly, environmentally safe, and biodegradable products as mosquito larvicides ${ }^{7}$. Natural products from plants have been evaluated as prototypes for new insecticidal agents, as they comprise a rich source of bioactive compounds that are potentially suitable for utilization in integrated management programs ${ }^{8}$. Consequently, the present study was undertaken to investigate the larvicidal potential of root and leaf extracts of $S$. costus against the early $4^{\text {th }}$ instar larvae of An. stephensi, Ae. aegypti, and Cx. quinquefasciatus, as possible control measures to prevent the incidence of vector-borne diseases. This is the first study of its kind, reporting the larvicidal activities of root and leaf extracts of $S$. costs against the tested mosquito vectors.

The roots and leaves of Saussurea costus (Falc.) Lipsch. were gathered in the month of August, 2016, from Jahama $\left(34.198^{\circ} \mathrm{N}\right.$ $74.364^{\circ} \mathrm{E}$ ), the Baramulla district, Jammu and Kashmir, India. Then, $500 \mathrm{~g}$ of powdered plant material that was packed inside a Soxhlet apparatus was subjected to $72 \mathrm{~h}$ of successive extraction using threefold of solvent systems, like petroleum ether, chloroform, ethyl acetate, and methanol. The pooled extracts were evaporated under reduced pressure at $40{ }^{\circ} \mathrm{C}$ by a rotary evaporator (HeidolfGermany) and stored at $4{ }^{\circ} \mathrm{C}$ until further assay. The voucher 
specimen (AUBOT\#347) is deposited at the herbarium, Department of Botany, Annamalai University.

The eggs of Anopheles stephensi Liston. and Aedes aegypti Linn., and the egg rafts of Culex quinquefasciatus Say. were procured from the Center for Research in Medical Entomology (ICMR-Government of India), Madurai, and reared in the laboratory $\left(29 \pm 3{ }^{\circ} \mathrm{C}, 75\right.$ to $85 \%$ $\mathrm{RH}$ ) by feeding with Brewer's yeast/dog biscuits (1:3). The eggs/egg rafts were used for a larvicidal bioassay at the early $4^{\text {th }}$ instar larval stage, as per the standard procedures recommended by the $\mathrm{WHO}^{9}$. The mortality of the larvae was also checked using control groups (water and DMSO). Probit analyses (SPSS, version 21.0) were used for calculating the lethal concentrations, $\mathrm{LC}_{50}$ and $\mathrm{LC}_{90}$, and their $95 \%$ confidence limit of upper and lower confidence levels.

To determine whether $S$. costus possess a larvicidal effect against the early $4^{\text {th }}$ instar larvae of the selected mosquito species, the larvae were exposed to different root and leaf extracts of $S$. costus in a concentration dependent manner during 12 and $24 \mathrm{~h}$ of exposure. Varied levels of larvicidal activities were observed for all tested extracts, while there were no recorded larval mortalities during the control treatments (DMSO and water). Among the different extracts of $S$. costus roots, the methanol extract recorded the highest larval mortality. After $12 \mathrm{~h}$ of exposure, the root methanol extract had $\mathrm{LC}_{50}$ and $\mathrm{LC}_{90}$ values of 10.70 and 53.91 ppm for An. stephensi,14.97 and $108.15 \mathrm{ppm}$ for Ae. aegypti, and 23.90 and $185.03 \mathrm{ppm}$ for Cx. quinquefasciatus, respectively. After $24 \mathrm{~h}$ of exposure, the root methanol extract had $\mathrm{LC}_{50}$ and $\mathrm{LC}_{90}$ values of 7.96 and34.39 ppm for An. stephensi, 10.79 and 60.71 ppm for Ae. aegypti, and 15.31 and 105.63 ppm for $C x$. quinquefasciatus, respectively. The larvicidal activity of the methanol extract was followed by that of petroleum ether $>$ chloroform and ethyl acetate extracts of S. costus after 24 $\mathrm{h}$ of exposure (Figure 1).

The larvicidal activity of the petroleum ether leaf extract of $S$. costus was higher than that of the other leaf extracts tested against An. stephensi, Ae. Aegypti, and Cx. quinquefasciatus. After $12 \mathrm{~h}$ of exposure, the petroleum ether leaf extract had $\mathrm{LC}_{50}$ and $\mathrm{LC}_{90}$ values of 27.83 and184.82 ppm for An. stephensi,62.73 and $249.03 \mathrm{ppm}$ for Ae. aegypti, and 87.56 and $269.59 \mathrm{ppm}$ for Cx. quinquefasciatus, respectively. After $24 \mathrm{~h}$ of exposure, the petroleum ether leaf extract had $\mathrm{LC}_{50}$ and $\mathrm{LC}_{90}$ values of 17.72 and $138.32 \mathrm{ppm}$ for An. stephensi, 23.49 and $172.91 \mathrm{ppm}$ for Ae. aegypti, and 50.12 and $165.77 \mathrm{ppm}$ for $C x$. quinquefasciatus, respectively. The larvicidal activity of the petroleum ether extract was followed by that of methanol $>$ chloroform and ethyl acetate extracts after $24 \mathrm{~h}$ of exposure (Figure 2).

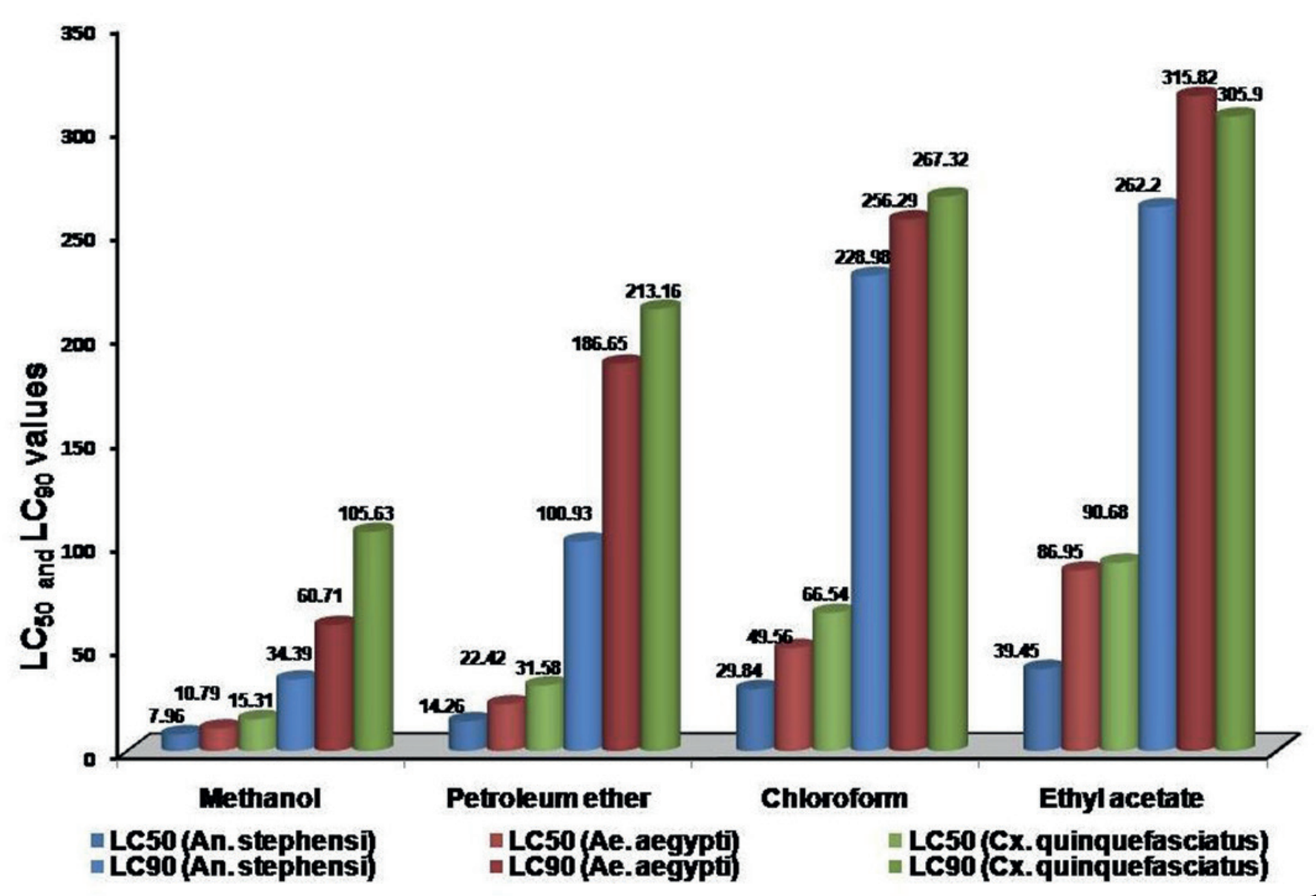

FIGURE 1: Larvicidal potential of Saussurea costus root extracts against An. stephensi, Ae. aegypti, and Cx. quinquefasciatus. 


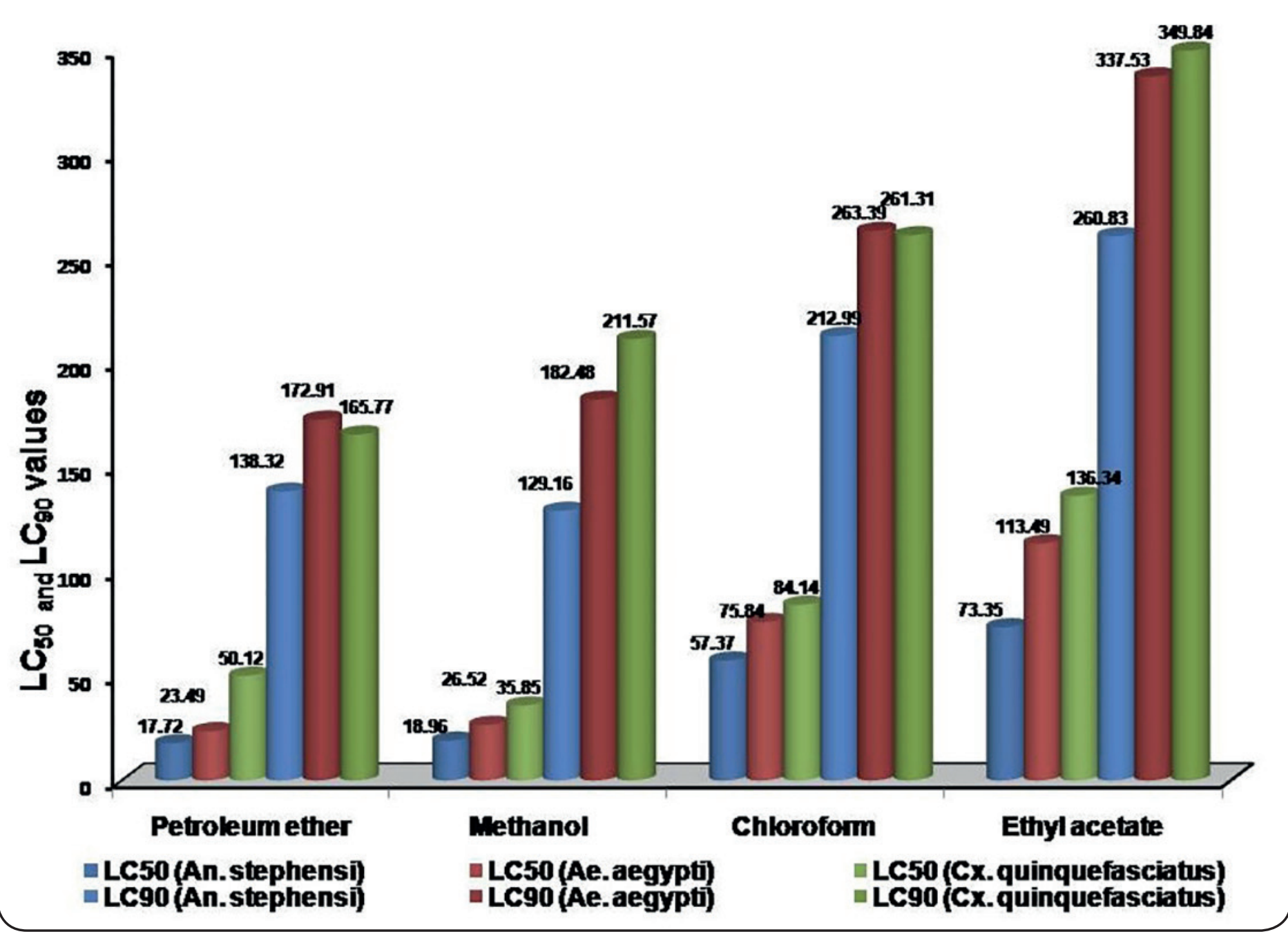

FIGURE 2: Larvicidal potential of Saussurea costus leaf extracts against An. stephensi, Ae. aegypti, and Cx. quinquefasciatus.

Dehydrocostus lactone and costunolide, isolated from the essential oils of the roots of $S$. costus, strongly support the theory that $S$. costus could be an effective larvicidal plant, as they exhibit strong larvicidal activity against Ae. albopictus with $\mathrm{LC}_{50}$ values of 2.34 and $3.26 \mu \mathrm{g} / \mathrm{mL}$, respectively ${ }^{10}$. In addition, An. stephensi and Ae. aegypti larvae were found to be more susceptible to plant extracts than other mosquito species, since the methanol extract of Terminalia chebula was more effective against An. stephensi $\left(\mathrm{LC}_{50}=87.13 \mathrm{ppm}\right)$ and Ae. Aegypti $\left(\mathrm{LC}_{50}=93.24 \mathrm{ppm}\right)$ than Cx. Quinquefasciatus $\left(\mathrm{LC}_{50}=111.98 \mathrm{ppm}\right)^{11}$. Additionally, Ramya et $\mathrm{al}^{12}$ observed the highest larval mortality from the ethyl acetate fraction of a leaf extract of Catharanthus roseus, followed by the methanol fraction against the I, II, III, IV, V, and VI instar larvae of Helicoverpa armigera. Similar to our results, among the different extracts tested, the methanol extract of the roots of $R$. cordifolia was more potent against $C x$. quinquefasciatus, with $\mathrm{LC}_{50}$ and $\mathrm{LC}_{90}$ values of 95.69 and $347.96 \mathrm{mg} / \mathrm{L}$, respectively ${ }^{13}$. Moreover, the methanol extract of Andrographis echioides had a higher toxicity against Ae. Aegypti $\left(\mathrm{LC}_{50}=93.00\right.$ and $\left.\mathrm{LC}_{90}=83.06 \mathrm{ppm}\right)$ than against Cx. quinquefasciatus $\left(\mathrm{LC}_{90}=171.81 \text { and } \mathrm{LC}_{90}=171.76 \mathrm{ppm}\right)^{14}$.
Likewise, the petroleum ether extract of the leaves of Ruta graveolens showed the highest larvicidal activity against An. stephensi, having an $\mathrm{LC}_{50}$ value of $31.89 \mu \mathrm{g} / \mathrm{mL}$ and $\mathrm{LC}_{90}$ value of $66.96 \mu \mathrm{g} / \mathrm{mL}$, while it had an $\mathrm{LC}_{50}$ value of $66.96 \mu \mathrm{g} / \mathrm{mL}$ against Ae. aegypti after $24 \mathrm{~h}$ of exposure ${ }^{15}$. In another study, the larvicidal efficacy of the ethanol, acetone, and petroleum ether extracts of the leaves of Tribulus terrestris were studied against $3^{\text {rd }}$ instar larvae of Ae. aegypti. Among the other tested extracts, the petroleum ether extract was found to be the most effective, with an $\mathrm{LC}_{50}$ value of $64.6 \mathrm{ppm}^{16}$.

The present work demonstrates that $S$. costus could be considered as a novel and effective source for use in vector control programs because of its biocidic effect against the larval stages of An. stephensi, Ae aegypti, and Cx. quinquefasciatus at low concentrations. The compound(s) responsible for the larvicidal activity should be isolated from the methanol extract of the roots of $S$. costus through bioassay-guided fractionation, which is under way in our laboratory. 


\section{ACKNOWLEDGEMENTS}

We are thankful to the Director of the Centre for Research in Medical Entomology (ICMR-Government of India), Madurai, for the supply of mosquito eggs/rafts.

\section{AUTHOR'S CONTRIBUTION}

Both authors equally contributed to the paper.

\section{CONFLICT OF INTEREST}

The authors declare that there is no conflict of interest.

\section{REFERENCES}

1. Mayer SV, Tesh RB, Vasilakis N. The emergence of arthropod-borne viral diseases: A global prospective on dengue, chikungunya and zika fevers. Acta Trop. 2017;166:155-3.

2. World Health Organization. Mosquito control: can it stop Zika at source? WHO: Geneva: 2016.

3. Jayaprasad B, Sharavanan S, Veerakumar K. Effect of Chloroxylon swietenia bark extracts against Culex quinquefasciatus, Aedes aegypti and Anopheles stephensi larvae. Parasitol Res. 2015;114(11):4219-23.

4. Panneerselvam C, Murugan K, Kovendan K, Mahesh PK, Subramaniam J. Mosquito larvicidal and pupicidal activity of Euphorbia hirta Linn.(Family:Euphorbiaceae) and Bacillus sphaericus against Anopheles stephensi Liston. (Diptera: Culicidae). Asian Pac J Trop Med.2013;6(2):102-9.

5. World Health Organization. Dengue and Severe Dengue. Fact Sheet No. 117. WHO, Geneva: 2014.

6. Gyapong J, Gyapong M, Yellu M, Anakwah K, Amofah G, Bockarie M, et al. Integration of control of neglected tropical diseases into health-care systems: challenges and opportunities. Lancet. 2010;375(9709):160-5.

7. Maharaj R, Maharaj V, Crouch NR, Bhagwandin N, Folb PI, Pillay $\mathrm{P}$, et al. Screening for adulticidal bioactivity of South African plants against Anopheles arabiensis. Malar J. 2011; 10: 233. http://dx.doi. org/10.1186/1475-2875-10-233.

8. Hwang SKI, Kim YK, Park KW, Kim YT. Piperolein B and piperchabamide D isolated from black pepper (Piper nigrum L.) as larvicidal compounds against the diamond back moth (Plutellaxylostella). Pest Manag Sci. 2017;73(8):1564-67.

9. World Health Organization. Guidelines for laboratory and field testing of mosquito larvicides. Communicable disease control, prevention and eradication, WHO pesticide evaluation scheme. Geneva, 2005.

10. Liu ZL, Qing H, Chu SS, Wang CF, Shu SD, Zhi WD. Essential oil composition and larvicidal activity of Saussurea lappa roots against the mosquito Aedes albopictus (Diptera: Culicidae). Parasitol Res. 2012;110(6):2125-30.

11. Veni T, Pushpanathan T, Mohanraj J. Larvicidal and ovicidal activity of Terminalia chebula Retz. (Family: Combretaceae) medicinal plant extracts against Anopheles stephensi, Aedes aegypti and Culex quinquefasciatus. J Parasit Dis. 2016;41(3):693-02.

12. Ramya S, Rajasekaran C, Kalaivani T, Sundararajan G, Jayakumararaj R. Biopesticidal effect of leaf extracts of Catharanthus roseus L. (G.) Don. on the larvae of gram pod borer - Helicoverpaar migera (Hübner). Ethnobot Leaflets. 2008;12:1096-1101.

13. Munusamy RG, Appadurai DR, Kuppusamy S, Michael GP,Savarimuthu I. Ovicidal and larvicidal activities of some plant extracts against Aedes aegypti L. and Culex quinquefasciatus Say (Diptera: Culicidae). Asian Pac J Trop Dis. 2016;6(6):468-71.

14. Mathivanan D, Rajiv GP, Regina MR, Suseem SR. Larvicidal and acaricidal efficacy of different solvent extracts of Andrographis echioides against blood-sucking parasites. Physiol Mol Plant Path. 2017;101:187-96.

15. Chacko A, Christy PH, Kavya KS. Study on larvicidal activity of crude extracts of Ruta graveolens against Aedes aegypti and Anopheles stephensi. Int J Mos Res. 2015; 2(4):01-06.

16. El-Sheikh TMY, Al-Fifi ZIA, Alabboud MA. Larvicidal and repellent effect of some Tribulus terrestris L. (Zygophyllaceae) extracts against the dengue fever mosquito, Aedes aegypti (Diptera:Culicidae). J Saud Chem Soc. 2016;5(1):13-22. 